\title{
Mexico - Corn Syrup \\ Mexico - Anti-dumping Investigation of High Fructose Corn Syrup from the United States, Recourse to Article 21.5 of the DSU by the United States*
}

\author{
ROBERT HOWSE AND DAMIEN J. NEVEN
}

\section{Introduction and summary of main legal issues}

The 21.5 AB ruling in Mexico - Corn Syrup arises out of a dispute between the United States and Mexico concerning whether the Mexican agency's finding of material injury from dumping was consistent with the Anti-dumping Agreement. The original Panel ${ }^{1}$ found that the agency's determination of the existence of a threat of material injury to the domestic industry was made in violation of numerous provisions of the Anti-dumping Agreement. In light of these findings by the panel, the agency made a redetermination and the United States filed a 21.5 complaint, claiming that the redetermination failed to address adequately the defects identified by the original panel.

The 21.5 Panel $^{2}$ agreed with the United States that an objective and unbiased agency could not infer the projected increase in imports asserted by the Mexican agency from the evidence on the record, and reached the same conclusion concerning the projections of the effects of these increases on the domestic industry. Here the issue was whether Mexico had analyzed various factors affecting demand for imports and the state of the domestic industry pursuant to Articles 3.4 and 3.7 of the Anti-dumping Agreement and whether the analysis, to the extent that it was done, would allow an objective and unbiased agency to come to the conclusion concerning threat of injury that the Mexican agency did come to.

* This study was prepared in the context of the project of the American Law Institute on the Principles of World Trade Law.

${ }^{1}$ Mexico - High Fructose Corn Syrup, WT/DS132/R, adopted February 24, 2000.

2 WT/DS132/RW, June 22, 2001. 
These aspects of the dispute engage the considerations in the interpretation of the Anti-dumping Agreement that we discuss in the introduction of our comment on Argentina - Ceramic Tiles, including, obviously, the standard of review prescribed in 17.6(i)-(ii) of the Anti-dumping Agreement. However, upon appeal, Mexico raised a number of other issues of a preliminary and procedural nature, including the impact on the panel proceedings of the US failure to engage in consultations, the meaning of the requirement in DSU 3.7 that a Member exercise self-restraint in bringing dispute settlement claims, and the requirement that the Panel give reasons for its conclusions that is contained in Article 12 of the DSU.

\section{The analysis of threat of material injury under the Anti-dumping Agreement: the significance of 3.4 and 3.7 and standard of review}

\subsection{Background}

High fructose corn syrup is the product allegedly dumped on the Mexican market by US producers. In its determination, Mexico focused on sugar as the "like" product that would be affected by the imports of high fructose corn syrup. High fructose corn syrup appears to be a substitute for sugar for particular segments of consumers, in particular for soft drink bottlers but also for other industrial users. Soft drink bottlers accounted for $68 \%$ of high fructose corn syrup imports in 1996 (the year for which evidence is gathered by the Mexican agency); producers of other beverages accounted for another 13\%, whereas other industrial users (outside the drinks industry) accounted for the remaining $19 \%$.

Imports of high fructose corn syrup increased markedly in 1996. Soft drink bottlers as well as other users apparently increased their purchases abroad. It appears however that in 1997 soft drink bottlers reached an agreement with sugar producers such that, in return for favorable sugar prices, they would limit their purchase of high fructose corn syrup, to less than 350,000 tons per year, which would appear to correspond approximately to the level of their purchases in 1996.

In its original determination and subsequent redetermination, Mexico did not dispute the existence of the agreement. Mexico thus claimed that even if the agreement existed and was implemented as of 1997, imports would increase significantly and would cause injury. Mexico still based its expectations of future import growth on the observation of a significant increase in 1996 (a period during which there was no agreement). 
Mexico did not provide evidence on the proportion of high fructose corn syrup that was purchased by the soft drink bottlers: the evidence on this matter was only provided in the course of the original Panel proceedings as answers to questions put forward by the Panel (see paragraph 7.176 of the original panel ruling). Mexico did not provide evidence either on the extent to which other producers would be able to substitute high fructose corn syrup for sugar (evidence was also provided during the proceedings, as a result of questions by the Panel). In order to establish injury, Mexico presented the amount of sugar that could be substituted in favor of high fructose corn syrup, as a proportion of the amount of sugar purchased by industrial users. By excluding the final consumption of sugars (sales to final users), Mexico of course obtained a larger figure.

The Panel ruled that Mexico's analysis did not meet the requirement of the Anti-dumping Agreement because the final consumption of sugar should have been considered to evaluate injury and because Mexico should have analyzed the state of the sugar industry more thoroughly. Furthermore, the Panel ruled that Mexico's consideration of the potential effects of the alleged restraint agreement was inadequate. In particular, at paragraph 7.177:

7.177 Mexico's contention that users of imported high fructose corn syrup other than soft-drink bottlers could have increased their consumption in amounts sufficient to constitute a substantial increase in imports is in our view questionable. However, even assuming this to be the case, there is no discussion in the final determination of the share of imports and domestic production consumed by soft-drink bottlers, other beverage manufacturers, and other industrial users, and the degree of substitutability of high fructose corn syrup and sugar in their products. Moreover, the alleged restraint agreement affected purchasers accounting for 68 per cent of the imports, suggesting that it would at least slow any further increases in imports. In addition, most other purchasers' ability to substitute high fructose corn syrup for sugar was limited, suggesting that, if the alleged restraint agreement existed, any further increases in imports would be less than they had been in the past. None of these elements is addressed in SECOFI's final determination. We note, moreover, that the final determination states that the alleged restraint agreement does not rule out the possibility that bottlers and other users would continue their purchases of imported high fructose corn syrup. However, not ruling out the possibility that imports would continue does not support the conclusion that there is a likelihood of substantially increased importation, as provided for in Article 3.7(i).

(emphasis added) 
The Panel was thus concerned that, if the agreement were implemented, imports of high fructose corn syrup would not grow much further in 1997 relative to the level they reached in 1996. Implicitly, the Panel however assumes that the presence of the agreement does not alter the benchmark against which increases in imports should be assessed. By comparing levels in 1996 and 1997, and arguing the latter may not grow relative to the former, the Panel assesses them against the same benchmark. That is, the Panel does not contemplate the possibility that imports of high fructose corn syrup in the presence of an agreement should be compared to the level of sugar consumption outside the soft-drink industry. It would appear that according to the Panel, the level of imports by users other than soft-drink producers should be considered in relation to total sugar consumption, including that of soft-drink producers. The Panel thus rejects an approach whereby the effects of imports are considered segment by segment. The Panel's rejection of segmentation is further underlined by its insistence (see above) that purchases of sugar for final consumption should be considered in addition to purchases by industrial users.

In its redetermination, Mexico addressed the specific points listed by the Panel. In particular, Mexico provided evidence on the share of imports and domestic production, the degree of substitutability and the effects of the restraint agreement. However, Mexico did not provide much further evidence on its essential claim, namely that users other than soft-drink bottlers would continue to shift away from sugar ${ }^{3}$.

The compliance Panel thus found that (paragraph 6.23):

\begin{abstract}
SECOFI's determination that industries other than soft-drink bottlers would undertake a massive shift from sugar use to high fructose corn syrup use, resulting in total consumption of high fructose corn syrup beyond the capacity of the domestic industry to supply, and a consequent significant increase in dumped imports, is not, in our view, one that could be reached by an unbiased and objective investigating authority in light of the evidence relied upon and the explanations given in the redetermination. While in its redetermination SECOFI did set out additional information
\end{abstract}

${ }^{3}$ It is beyond the scope of this comment to fully discuss the evidence submitted by Mexico on this point. However, it would appear that the evidence suffered from very important shortcomings, that were rightly pointed out by the Panel. Mexico appeared to have considered a sample of firms using both sugar and high fructose corn syrup. It had then assumed that the level of overall imports would reflect the proportion observed for these firms but subsequently discounted the overall level by 50 percent. This method appears to be rather arbitrary and does not focus on the right question, namely the extent to which firms have responded to relative prices of sugar and high fructose corn syrup. 
concerning the points identified by the Panel as problematic in its original report, SECOFI failed to provide a reasoned explanation of how that information supports the conclusion that there was a significant likelihood of increased imports. We therefore determine that SECOFI's conclusion that there was a significant likelihood of increased importation is not consistent with Article 3.7(i) of the AD Agreement.

In its appellate submission, Mexico claimed that the compliance Panel had erred in relying on a conjecture about the existence of the agreement between sugar and soft-drink producers, whereas Article 3.7 of the Anti-dumping Agreement stipulates that "a determination of a threat of material injury shall be based on facts and not merely on allegation, conjecture or remote possibility."

Effectively, what Mexico seems to argue is that the Panel should not have relied on the same assumption as Mexico (!) with respect to the existence of the agreement and should have assumed that the agreement did not exist. In what follows, we will argue that the Panel failed to properly analyze the effects of the alleged agreement and as a consequence may not have given sufficient credit to the analysis of injury put forward by Mexico.

\subsection{The alleged restraint agreement}

The alleged agreement between sugar producers should be seen as a decision by sugar producers to discriminate between different buyers of sugar. The emergence of high fructose corn syrup as a substitute for sugar for some industrial uses, and in particular for the preparation of soft drinks, has increased the price elasticity of demand for sugar in those particular segments. In these circumstances, it should be expected that sugar producers will try to discriminate across segments and offer discounts only in those segments that have become more price elastic. Presumably, before the emergence of high fructose corn syrup as a potential substitute, sugar producers did not perceive different price elasticities across segments and charged a single price. Matters changed when high fructose corn syrup was introduced, which only affected demand for a particular segment.

It is not clear why an agreement was necessary ${ }^{4}$ in order to implement such price discrimination. In the presence of different demands that can be readily identified, oligopolists can in principle achieve third-degree

${ }^{4}$ The legality of this agreement with respect to Mexican antitrust laws would appear to be questionable (the issue was however not raised by the panel and $\mathrm{AB}$ rulings). 
price discrimination without recourse to an agreement. If indeed the agreement was superfluous to achieve price discrimination, its existence was unimportant to evaluate the change in imports and possibly did not deserve the attention that it was given by the Panel. That is, the normal reaction of sugar producers such that they would offer discounts to those segments for which high fructose corn syrup was an alternative, would have reduced the pace of imports in the absence of an agreement.

However, the presumption that the agreement was superfluous is not satisfactory and the Panel should possibly have considered the matter further. One can only speculate about the circumstances that may have led to the implementation of the agreement but different explanations will entail different consequences for the analysis of potential imports and the analysis of injury. For instance, one hypothesis may be that firms had to reach an agreement in order to avoid arbitrage across segments. Contracts with soft drinks buyers that prevent resale to other users would effectively prevent arbitrage but may not be profitable for each firm taken individually. This may arise if the cost of arbitrage is mainly felt by competitors (who will lose custom as a consequence of the arbitrage). This is particularly likely if there are many firms in the industry and if firms' offerings are not differentiated. In those circumstances, the prevention of arbitrage, which is necessary to enforce third-degree price discrimination, may require the enforcement of an agreement whereby each firm commits to prevent soft-drink buyers from reselling to other users. If this interpretation is correct, the existence of the agreement would affect the analysis of imports since, in the absence of an agreement, discrimination would not have been feasible and imports would have increased further.

There are, however, alternative explanations behind the existence of an agreement, which may not affect the flow of imports, but would still affect the analysis of injury. One alternative hypothesis is that producers may have felt that an agreement was necessary in order to maintain a collusive understanding in the industry. There may have been a concern in the industry that faced with new competition, the ongoing collusive understanding could be jeopardized for instance because individual discounts given to producers of soft drinks could have been perceived as a defection from the collusive understanding. An agreement may thus have served the purpose of providing a new focal point on which firms would coordinate their behavior. It is unclear how the agreement would affect the flow of imports - it all depends on the extent to which the level of discounts may have been coordinated. But the analysis of injury in those circumstances 
would clearly be affected; in the absence of an agreement, imports of high fructose corn syrup would have destabilized collusion by local firms and arguably may have brought benefits to local consumers and possibly may have increased domestic welfare. Hence, if injury is evaluated in terms of the profits of the domestic firms, the agreement would have reduced injury. But if injury is evaluated in terms of consumer surplus of welfare, the agreement would have increased injury.

\subsection{Market segmentation}

As discussed in the previous section, it is not clear that an agreement was necessary to undertake third-degree price discrimination but it is likely that third-degree discrimination across different segments would take place as a consequence of the emergence of high fructose corn syrup as a substitute for some industrial uses, including soft-drink production.

This raises a broader question, namely whether the imports of high fructose corn syrup should be assessed relative to the sales of sugar in the segment affected or relative to the overall sales of sugar. As emphasized above, the panel has insisted both the sugar sales for final consumption should be considered in the analysis of injury but also that the level of imports in 1997 (when there was an agreement) should be considered against the same benchmark as those in 1996. That is, the panel has firmly rejected an analysis of the particular segment affected by the substitution in favor of high fructose corn syrup.

Whether a focus on the segment of sugar sales affected by high fructose corn syrup was appropriate could also be interpreted as raising the question of whether the "like" products should not have been defined as the sugar sold in that particular segment rather than as sugar in general.

It would seem that if price discrimination can indeed be enforced, most of the economic effects of the substitution with high fructose corn syrup will be felt in that particular segment. Buyers of sugar in other segments (including final users) will be affected to a much lesser extent: the price that they pay will be affected only in so far as the elasticity that firms will face in those segments will change (assuming constant marginal costs). But if the elasticity that firms faced in the two segments was identical before the introduction of high fructose corn syrup (such that no discrimination was enforced), the elasticity that firms will face in the segments not affected by it will not change. Similarly, the profit that firms make will only be reduced from the sales in the segments affected by high fructose corn syrup. Hence, it would seem that the analysis should be carried out in the 
segment affected by the syrup and more generally that the "like" product should have been defined as sugar sold in those segments. ${ }^{5}$ It would thus appear that the panel erred in insisting that Mexico should have carried out its analysis for the entire sugar market.

\subsection{Should the Panel assume that the agreement existed?}

As mentioned above, in its appellate submission, Mexico also claimed that the compliance panel had erred in relying on a conjecture, with respect to the existence of the agreement between sugar and soft-drink producers, whereas Article 3.7 of the Anti-dumping Agreement stipulates that "a determination of a threat of material injury shall be based on facts and not merely on allegation, conjecture or remote possibility."

The $\mathrm{AB}$ disagreed and emphasized that, in choosing to base its argument on the assumption that the agreement existed, Mexico treated it as a fact. Since Mexico chose to assume the existence of the agreement for the purpose of its analysis, it would, according to the $\mathrm{AB}$, have been "improper for the Panel to have sought, on its own initiative, to go behind the assumptions made by SECOFI."

The attitude of the $\mathrm{AB}$ seems appropriate. In general, it would seem reasonable to ask the Panel to give some deference to the agency's assumptions, given 17.6. But here the agency in its actual analysis had relied on the opposite assumption, namely that the restraint agreement did in fact exist. In affirming the Panel's decision, the AB here displays a proper understanding of the meaning of 17.6. The correct approach to review agency determinations is not to ask whether the Panel, if acting in the place of the agency, could or would properly come to a different or the same conclusion, but rather whether the actual analysis done by the agency is such as could be made by an objective and unbiased decision maker. Thus the Panel in the first instance must accept the agency's assumptions (provided they are not patently unreasonable) and examine whether, based on such assumptions, the conclusions the agency draws are such as could be drawn by an objective and unbiased decision maker.

\subsection{Consultations}

Mexico claimed on appeal that the Panel's failure to address the significance of the lack of consultations between the United States and Mexico

\footnotetext{
${ }^{5}$ Market definition in the antitrust field adopts a similar approach. Particular segments are normally considered as separate relevant markets when price discrimination is feasible.
} 
prior to the referral of the dispute to the Panel was an error that was fatal to the panel's jurisdiction or authority over the entire matter. However, as noted by the Appellate Body, Mexico never mentioned this issue in its written submissions to the Panel, and only raised it in oral argument, without actually making any specific claim concerning the legal effect of the failure to engage in consultations. Moreover, when the US submitted a request for a 21.5 Panel to the Dispute Settlement Body (DSB), Mexico not only did not object, but rather stated explicitly to the DSB that it "decided not to oppose the US request at the present meeting" ( $\mathrm{AB}$ Report, paragraph 39).

As a general matter of procedure the $\mathrm{AB}$ held that the Panel was not required to address the issue of lack of consultations because Mexico had simply failed to bring that issue before the panel as a "claim." The AB noted: "The requirements of good faith, due process and orderly procedure dictate that objections, especially those of such potential significance should be explicitly raised. Only in this way will the Panel, the other party to the dispute, and the third parties, understand that a specific objection has been raised, and have an adequate opportunity to address and respond to it" (paragraph 47).

However, as the $\mathrm{AB}$ pointed out, even if the parties have not raised any objections, a panel is still required to examine, on its own motion as it were, whether it has jurisdiction or authority over the matter. The $\mathrm{AB}$ held that prior consultations were not a condition precedent to the Panel having jurisdiction over the matter, and therefore that the Panel was not required to address the lack of consultations on its own motion. The AB's reasoning here seems to be ironclad: it was able to point to various provisions of the DSU that indicate in certain circumstances the possibility of consultations being waived by consent of the parties. Thus, it cannot be the case that the prior consultations are a pre-condition for the Panel to assume jurisdiction, regardless of the conduct and wishes of the parties in regard to consultations.

Because it held that (1) the Panel did not have to address the consultation issue as a "claim" of Mexico since Mexico did not make this claim explicitly; and that (2) the Panel did not have to address it anyway as a threshold jurisdictional issue, the $\mathrm{AB}$ never actually got to the underlying interpretive issue of whether under the DSU there is a legal requirement of prior consultations before requesting a 21.5 panel.

Mexico also claimed on appeal that the Panel erred in failing to address the situation that the United States on its request for a panel had failed to explicitly state whether consultations had been held. Article 6.2 of the 
DSU provides that a request for establishment of a panel "shall indicate whether consultations were held ..." The AB held that since Mexico had not stated this issue either as an explicit "claim" to the Panel, and since this issue did not go to jurisdiction either, the Panel was under no obligation to address it. Again, the $\mathrm{AB}$ stressed that it did not need to reach the underlying substantive interpretative issue of whether this requirement of 6.2 applied to requests for 21.5 panels.

Does the AB's treatment of the consultations issue tell us anything about how it thinks that the Panel should have dealt with this issue had it been properly before the Panel as a "claim" by Mexico that the United States had violated the DSU? Arguably, the implication of holding that this is not a jurisdictional issue is that, were the Panel to find a violation of this provision of the DSU, it would not dismiss the action, but provide some other kind of relief to Mexico. The obvious form of such relief would be a suspension of Panel proceedings pending the required consultations. Is such relief within the ambit of a Panel's powers?

An alternative view, which is suggested by the fact in this case that at the DSB meeting Mexico did not object to the US request for a Panel, is that enforcement of the consultations requirement appropriately occurs when the DSB has the request for a Panel before it. This would make sense of the requirement in DSU 6.2, discussed above, that in its request, a Member indicate whether consultations have taken place. In the absence of prior consultations, the DSB may not be properly seized of the request for a Panel; since the agenda for a DSB meeting is agreed by consensus, the would-be-defendant could effectively, and with justification, object to the request for a Panel being on the agenda of a particular meeting, given the absence of prior consultations. ${ }^{6}$

\subsection{Member self-restraint in recourse to dispute settlement}

Article 3.7 of the DSU provides, in part, "[b]efore bringing a case a Member shall exercise its judgment as to whether action under these procedures would be fruitful." The AB held that here too Mexico had not raised the question concerning fruitfulness of dispute settlement

${ }^{6}$ This blocking power may not be used in order to frustrate the right to dispute settlement; but the point here is that any such right is subject to the condition of prior consultations. Thus, preventing consensus on the agenda in this special situation in order to enforce the condition of prior consultations would arguably be consistent with the letter and spirit of the law. 
procedures as a "claim." Such a matter would not go to the jurisdiction of the panel, the $\mathrm{AB}$ held, because the notion of exercising one's judgment is inherently self-regulating. Thus - and here the $\mathrm{AB}$ cited its ruling in $E C$ Bananas III on a similar issue - "Article 3.7 neither requires nor authorizes a panel to look behind that Member's decision and to question its exercise of judgment."

This ruling, while fairly obvious, nevertheless drives home a basic reality of the dispute settlement system overlooked by critics of the Appellate Body and the panels such as Claude Barfield. ${ }^{7}$ These critics fault the tribunals for adjudicating claims that are more appropriately left to political negotiations or diplomatic processes in the WTO. These accusations of judicial activism are unfounded, as the law of the DSU as it is written does not provide a basis for the adjudicator second-guessing a Member's decision to go to dispute settlement. A Member has a right to have its claims decided by the tribunal. Given the clarity of the DSU on this point, it would be in fact illegitimate judicial activism for a tribunal to decline to adjudicate, on the basis that some other manner of dealing with the dispute would be more fruitful.

At the same time, in considering the legal effect of DSU Article 3.7, the $\mathrm{AB}$ did not discuss (and Mexico apparently did not raise) Article 3.10 which provides: "It is understood that requests for conciliation and the use of dispute settlement procedures should not be intended or considered as contentious acts and that, if a dispute arises, all Members will engage in these procedures in good faith in an effort to resolve a dispute." This provision does not have explicit language suggesting that it is exclusively self-policing. Even if it does not go to jurisdiction such that a panel would have to consider the matter on its own motion, does this language nevertheless perhaps confer on the panel a discretion to decline to adjudicate, if it believes that dispute settlement is being used as a "contentious act" or that there is bad faith? In other cases, in particular India - Quantitative Restrictions ${ }^{8}$ and Turkey - Textiles ${ }^{9}$ the $\mathrm{AB}$ has been very disinclined to adopt interpretations of WTO treaties that would limit or qualify a Member's right to go to dispute settlement. It appears to view this right as fundamental to the basic WTO bargain, and thus it would be surprising if

${ }^{7}$ Barfield (2001). See also, Roessler (2000).

${ }^{8}$ India-Quantitative Restrictions on Imports of Agricultural, Textile and Industrial Products, $W T / D S 90 / A B / R$, especially para. 83.

9 Turkey - Restrictions on Imports of Textile and Clothing Products, Report of the Appellate Body, WT/DS34/AB/R, paras. 58, 60 . 
language as soft as "it is understood..." would be considered sufficiently emphatic to qualify such a fundamental right.

\subsection{The requirement that the Panel provide reasons}

Article 12.7 of the DSU requires that the "report of the Panel shall set out the findings of fact, the applicability of relevant provisions and the basic rationale behind any findings and recommendations that it makes." Mexico maintained that in the Panel's scrutiny of the agency's analysis on redetermination with respect to threat of material injury, the Panel did not link its findings explicitly to discrete violations of Articles 3.4, 3.7, and 3.1 of the Anti-Dumping Agreement, and thus violated the strictures of DSU Article 12.7.

The $A B$ disagreed. It noted that in the original Panel report the Panel had set forth its view of the close relationship between these three provisions and thus that it was relatively straightforward to ascertain how the defects in the agency's analysis identified in the 21.5 report amounted to an application by the agency of those provisions in a manner that fell short of the deferential standards articulated in Article 17.6(ii) of the Anti-dumping Agreement.

The $A B$ is right. In fact, here (just as with its treatment of the assumption about the restraint agreement) the Panel proceeded exactly in the way that is appropriate given Article 17.6 and the nature of the obligations in the Anti-dumping Agreement. That is, it identified the relevant provisions of the Anti-dumping Agreement, and then focused on whether the agency's establishment of the facts was proper and its evaluation of them consistent with the conduct of an objective and unbiased decision maker, and whether the agency's interpretation of the Anti-dumping Agreement is "permissible" under the Vienna Convention on the Law of Treaties rules. In sum, once it identified the relevant provisions and explained why they were relevant to the dispute, it was logical and appropriate that the focus in the Panel's reasons would be on the actual analysis of the agency in its application of the provisions, judged against the Article 17.6 standard of review for agency decision making.

\subsection{Significance of the Panel's statement that it might be possible to} arrive at the result of the Mexican agency on the facts of the case

In paragraph 6.37 of its report, the 21.5 Panel acknowledged that its ruling did not stand for the proposition that "it would not be possible to make 
a finding of threat of material injury in the circumstances of this case." Mexico claimed on appeal that this statement constituted an admission, as it were, that the Panel was not applying properly the standard of review in Article 17.6; if indeed a finding of material injury was "possible" in this case, then the agency must be operating with a permissible interpretation of the Anti-dumping Agreement, Mexico argued, and therefore was entitled to deference under Article 17.6(ii).

The $\mathrm{AB}$ rejected this claim, preferring to interpret the Panel as merely saying that it was not judging the correctness of the agency's result, but rather finding fault with the analysis by which it came to that result. Here, the $A B$ (and indeed the Panel) again for once seem to have grasped something of the proceduralist nature or focus of agency review under the Anti-dumping Agreement. In reviewing whether, in the application of the relevant provisions of the Anti-dumping Agreement, the Agency's analysis is one that an unbiased and objective decision maker would be capable of, the panel is not to place itself in the role of an ideal Agency and actually engage in its own analysis of whether it is possible to find, for instance, a threat of material injury in the circumstances in question.

Examining the entire record de novo, it is entirely possible that an agency could, in applying the relevant provisions of the Anti-Dumping Agreement, make certain inferences from certain facts and come to a conclusion of threat of material injury. It is not up to the Panel to speculate on how that might be done, but only to determine whether the way in which this agency has actually drawn inferences from facts is consistent with the behavior of an objective and unbiased decision maker, applying the Anti-dumping Agreement in a manner consistent with the Vienna Convention rules. Again, the $\mathrm{AB}$ appears to have grasped the importance of a panel confining itself to the analysis the agency actually undertook, rather than the agency asking whether, if the agency itself were to redo the analysis, it would or could come to the same conclusion as the Panel.

\subsection{Parallel proceedings under the NAFTA: a non-issue}

In respect of the Mexican redetermination, the United States brought parallel proceedings under the North American Free Trade Agreement (NAFTA), chapter 19. Chapter 19 provides for panel review of agency decisions against the standard of administrative fairness and rationality that exists in the law of the country to which the agency belongs, in this case Mexico. Parallel proceedings had also been brought under NAFTA in respect of the original determination by the Mexican agency, and the 
NAFTA panel - albeit applying a rather different legal standard - made similar findings to those of the original WTO panel.

As a general rule, international law is permissive of parallel or overlapping proceedings in the same matter. ${ }^{10}$ The existence of the parallel NAFTA proceedings concerning the agency redetermination appears to have had no impact on either the Panel or the Appellate Body 21.5 ruling.

\section{Conclusion}

From a legal perspective, in its interpretation of the Anti-Dumping Agreement, and particularly the standard of review in Article 17.6, the AB in this decision seems not to have made some of the missteps that we identified in the introduction to our report on Argentina-Ceramic Tiles. A proper approach to Article 17.6 requires that the Panel take the analysis of the domestic agency as it finds it, and determine whether the agency's analysis is based on a permissible interpretation of the Anti-dumping Agreement, and conclusions of fact that an unbiased, objective decision maker would be capable of making based on the record in question.

What the $\mathrm{AB}$ shows in this ruling is that the correct approach to Article 17.6, while giving deference to the agency's actual decision, may in some circumstances result in an outcome less favorable to the defendant Member that has imposed anti-dumping duties - for even in cases where the Panel could itself redo the analysis of the agency to come to a finding of dumping and/or injury consistent with the Anti-dumping Agreement, Article 17.6 requires the Panel to limit its examination to whether the actual analysis and findings of the agency violate the Agreement. It is ironic and in some sense unfortunate (in terms of public perceptions of the dispute settlement process) that this one case where the $A B$ seems to have properly appreciated the character of Article 17.6 resulted in its application to the disadvantage of the defending government.

From an economic perspective, we have argued that the Panel below erred in not finding it relevant to examine the existence of an agreement on restraint of trade, and analyzing the effects of that agreement (if it existed) on the extent of injury. To return to the legal perspective, however, the Panel and the $\mathrm{AB}$ were faced with the actual analysis of the domestic

${ }^{10}$ See, for example, Southern Bluefin Tuna Case-Australia and New Zealand v. Japan, Award on Jurisdiction and Admissibility, August 4, 2000, Arbitral Tribunal constituted under Annex VII of the United Nations Convention on the Law of the Sea, para. 52. 
agency, which had assumed the existence of the restraint agreement as a fact.

Finally, from the economic perspective, a panel error not corrected by the $\mathrm{AB}$ was to decide that injury analysis must consider the industry in the broadest possible terms, and not take into account market segmentation. As we have argued, isolating the appropriate segment of the market may well enhance the accuracy of an analysis of injury in a case such as this.

\section{References}

Barfield, C., 2001. Free Trade, Sovereignty, Democracy: the Future of the World Trade Organization, Washington D.C.: AEI Press.

Roessler, F., 2000. “The Institutional Balance between the Judicial and the Political Organs of the WTO", in New Directions in International Economic Law: Essays in Honour of John H. Jackson, M. Bronckers and R. Quick, eds., Kluwer Law International, The Hague, pp. 325-46. 